\title{
Ability of Bicarbonate Supplementation to Sensitize Selected Methicillin-Resistant Staphylococcus aureus (MRSA) Strains to $\beta$-Lactam Antibiotics in an Ex Vivo Simulated Endocardial Vegetation Model
}

\author{
Warren E. Rose ${ }^{1 \#}$, Ana M. Bienvenida ${ }^{2}$, Yan Q. Xiong ${ }^{3,4}$, Henry F. Chambers ${ }^{5}$
}

Arnold S. Bayer ${ }^{3,4 \# \#, ~ S e l v i ~ C . ~ E r s o y ~}{ }^{3 \# \#}$

\footnotetext{
${ }^{1}$ School of Pharmacy, University of Wisconsin-Madison, Madison, Wl;

${ }^{2}$ Department of Pharmacy, UW Health, Madison, WI

${ }^{3}$ Los Angeles Biomedical Research Institute at Harbor-UCLA Medical Center, Torrance, CA

${ }^{4}$ David Geffen School of Medicine at UCLA, Los Angeles, CA

${ }^{5}$ University of California at San Francisco School of Medicine, San Francisco, CA
}

Running title: Ex vivo model of bicarbonate- $\beta$-lactam sensitization of MRSA

\#Corresponding author

Warren Rose, PharmD, MPH

School of Pharmacy, University of Wisconsin-Madison, 777 Highland Avenue, Room 4123, Madison, WI USA

Phone: 608.890.1917; Fax: 608.265.5421

Email:warren.rose@wisc.edu

\#\# - Contributed equally to this work

Keywords: $\beta$-lactams; methicillin resistance; Staphylococcus aureus; bicarbonate

Word Count: 3963 


\section{ABSTRACT}

Supplementation of standard growth media (cation-adjusted Mueller-Hinton Broth [CAMHB]) with bicarbonate $\left(\mathrm{NaHCO}_{3}\right)$ significantly increases $\beta$-lactam susceptibility of selected MRSA strains ("NaHCO 3 -responsive"). This "sensitization" phenomenon translated to enhanced $\beta$-lactam efficacy in a rabbit model of endocarditis. The present study evaluated $\mathrm{NaHCO}_{3}$ mediated $\beta$-lactam MRSA sensitization using an ex vivo pharmacodynamic model, featuring simulated endocardial vegetations (SEVs), to more closely mimic the host microenvironment. Four previously described MRSA strains were used: two each exhibiting in vitro " $\mathrm{NaHCO}_{3}$ responsive" or " $\mathrm{NaHCO}_{3}$-nonresponsive" phenotypes. Cefazolin (CFZ) and oxacillin (OXA) were evaluated in $\mathrm{CAMHB} \pm \mathrm{NaHCO}_{3}$. Intra-SEV MRSA killing was determined over $72 \mathrm{hr}$ exposure. In both $\mathrm{NaHCO}_{3}$-responsive strains, supplementation with $25 \mathrm{mM}$ or $44 \mathrm{mM} \mathrm{NaHCO}$ significantly reduced $\beta$-lactam MICs to below the OXA susceptibility breakpoint $(\leq 4 \mathrm{mg} / \mathrm{L}$ ) resulting in bactericidal activity ( $\geq 3$ log kill) in the model for both OXA and CFZ. In contrast, neither in vitrodefined $\mathrm{NaHCO}_{3}$-nonresponsive MRSA strains showed significant sensitization in the SEV model to either $\beta$-lactam. At both $\mathrm{NaHCO}_{3}$ concentrations, the fractional time-above-MIC was

$41>50 \%$ for both CFZ and OXA in the $\mathrm{NaHCO}_{3}$-responsive MRSA. Also, in RPMI+10\% LB media

42 (proposed as a more host-mimicking microenvironment and containing $25 \mathrm{mM} \mathrm{NaHCO}_{3}$ ), both

43 CFZ and OXA exhibited enhanced bactericidal activity against each $\mathrm{NaHCO}_{3}$-responsive strain

44 in the SEV model. Neither CFZ nor OXA exposures selected for high-level $\beta$-lactam-resistant 45 mutants within SEVs. Thus, in this ex vivo model of endocarditis, in the presence of $\mathrm{NaHCO}_{3}$ supplementation, both CFZ and OXA are highly active against MRSA strains that demonstrate similar enhanced susceptibility in $\mathrm{NaHCO}_{3}$-supplemented media in vitro. 


\section{INTRODUCTION}

Staphylococcus aureus is an important human pathogen that is associated with both

50

51

52

4

Despite development of newer anti-MRSA antibiotics over the past decades (e.g., daptomycin; linezolid; oritavancin; dalbavancin and ceftaroline) $(3,6)$, these agents have been problematic for several reasons, including: cost; toxicities; lack of proven efficacy in bacteremia and endocarditis; and/or evolution of resistance during therapy, associated with clinical failures (7-9). Therefore, clinicians continue to rely on exploring novel approaches with older antimicrobials with proven efficacy, such as multi-drug combination treatments (10). community- and nosocomial-associated infections. It is a major cause of skin, soft-tissue, respiratory, and bone and joint infections, and is the leading cause of bacteremia and endocarditis in industrialized countries $(1,2)$. In many geographic locales, methicillin-resistant Staphylococcus aureus (MRSA) are responsible for the majority of $S$. aureus bacteremias (3), especially in community-associated scenarios (4). The Centers for Disease Control and Prevention (CDCP) has deemed MRSA (particularly community-acquired MRSA) as a critical "concerning threat" to human health (5).

$$
\text { antimicrobials with proven efficacy, such as multi-drug combination treatments (10). }
$$

5

One of the limitations of antibiotic use is the predictive value of antimicrobial susceptibility testing and breakpoint determinations for selection. Although other diagnostics for infectious diseases have rapidly evolved over the past decade, antimicrobial susceptibility testing for MRSA has largely remained unchanged since the 1960s, with the use of bacterial growth medium such as Mueller-Hinton broth and agar (MHB; MHA). For MRSA susceptibility testing with oxacillin (OXA) to determine MRSA phenotype, the Clinical and Laboratory Standards Institute (CLSI) recommends growth of bacteria in $2 \% \mathrm{NaCl}$ cation-adjusted (CA)MHB $(11,12)$. Although this latter medium will amplify the capacity to isolate the OXA-resistant subpopulations within MRSA strains, it does not accurately reflect the host milieu; thus, the 
resulting minimum inhibitory concentrations (MICs) may not accurately represent antibiotic activity against MRSA within host-specific microenvironments (13).

Recent studies have focused on refining in vitro growth media in order to better simulate the host microenvironment in vivo in the context of more relevant and translatable antimicrobial susceptibility testing. Supplementation of standard media with bicarbonate $\left(\mathrm{NaHCO}_{3}\right), \mathrm{a}$ ubiquitous buffer in humans, has become the subject of several such studies $(13,14)$. These reports have demonstrated the ability of $\mathrm{NaHCO}_{3}$ to alter the susceptibility of selected MRSA strains in vitro to $\beta$-lactams. These investigations have focused on two conventional, prototype $\beta$-lactams not recommended for use against MRSA, OXA and cefazolin (CFZ) (14). These data enabled identification of two distinct MRSA phenotypes, $\mathrm{NaHCO}_{3^{-}}$"responsive" and $\mathrm{NaHCO}_{3}$ "nonresponsive". These in vitro phenotypes accurately predicted the ability of these same $\beta$-lactams to clear MRSA from multiple target tissues in a rabbit model of MRSA infective endocarditis (i.e., cardiac vegetations, kidneys and spleen) (14). The mechanism(s) by which $\mathrm{NaHCO}_{3}$ sensitizes "responsive" strains to such $\beta$-lactams appears to involve, at least in part, multiple genes which are critical in maintaining the MRSA phenotype, such as mecA and sarA (12); these perturbations may, in turn, lead to decreased production and/or maturation of PBP2a, yielding a "functional MSSA" phenotype (14).

The present study expands on our previous findings of bicarbonate sensitization of MRSA to $\beta$-lactams using a pharmacodynamic model featuring ex vivo simulated endocardial vegetations (SEVs). We hypothesized that 'bicarbonate responsiveness' in MRSA in this model would mirror similar findings in the rabbit endocarditis model, and that host-mimicking media within SEVs would help identify novel pharmacodynamic optimization strategies for prototypical $\beta$-lactams against such $\mathrm{NaHCO}_{3}$-responsive MRSA strains. 


\section{RESULTS}

$\beta$-lactam susceptibilities in standard and alternative media supplemented with $\mathrm{NaHCO}_{3}$. CFZ and OXA MICs have been previously reported for these four study strains (14). In this investigation, we confirmed the strain-dependent $\mathrm{NaHCO}_{3}$ enhancement of the susceptibility of these isolates to the two study $\beta$-lactams. As noted in Table 1, strains 11-11 (USA300) and MW2 (USA400) displayed a significant reduction in $\beta$-lactam MICs in media supplemented with $\mathrm{NaHCO}_{3}(44 \mathrm{mM})$, while $\beta$-lactam susceptibility was not affected with $\mathrm{NaHCO}_{3}$ supplementation for the other two strains, COL (USA100) and BMC-1001 (USA500). In the two $\mathrm{NaHCO}_{3}$-responsive strains, supplementation with $44 \mathrm{mM} \mathrm{NaHCO}$ reduced the $\mathrm{CFZ}$ MIC to below the OXA susceptibility breakpoint ( $\leq 4 \mathrm{mg} / \mathrm{L})$, with an 8-16-fold MIC reduction. Similarly, for these same strains, the OXA MICs were reduced 16-64-fold with $44 \mathrm{mM} \mathrm{NaHCO}_{3}$ supplementation.

It has recently been reported that an 'antibiotic sensitization' effect, especially for gramnegative bacteria and selected $\beta$-lactams, can occur in other host-mimicking media (13-15). The standard cell culture media, RPMI 1640, contains physiologic concentrations of $\mathrm{NaHCO}_{3}$ ( 25 mM). In this media, as opposed to CA-MHB, we noted substantially increased $\beta$-lactam susceptibility in all four strains regardless of genotypic background. However, the two $\mathrm{NaHCO}_{3}^{-}$ responsive strains were generally more responsive in this host-mimicking media, with resultant $\beta$-lactam MICs of $\leq 2 \mathrm{mg} / \mathrm{L}$ (Table 1), consistent with previous findings (14).

\section{$\beta$-lactam pharmacokinetics in the ex vivo SEV model. The pharmacokinetic profiles} of antibiotics within the ex vivo SEV model is computer designed to precisely mimic actual patient exposures clinically. Table 2 provides the predicted vs. observed pharmacokinetic profiles of CFZ and OXA in the SEV model's central 'fluid' compartment (media). We simulated high-dose CFZ administration ( $2 \mathrm{~g}$ every $8 \mathrm{hrs}$ ) and OXA (2 g every 6 hrs), as recommended for 
126

127

128

129

130

invasive MSSA infections $(16,17)$. The concentrations achieved in the ex vivo model closely correlated to the targeted parameters for both antibiotics.

Antimicrobial activity in the ex vivo SEV model. The antibiotic activities in the ex vivo SEV pharmacodynamic model are displayed in Figures 1-3; Table 3 compares the ability of each $\beta$-lactam to reduce the MRSA counts within the SEVs over the $72 \mathrm{hrs}$ course of treatment (expressed as the area under the bacterial curves, AUBC). As a point of reference, the less the AUBC, the more active the antibiotic regimen (18). The following trends emerged from these studies:

- $\quad \beta$-lactams were inactive against all MRSA in the ex vivo SEV model with CAMHB in the central compartment without bicarbonate supplementation. As expected, based on intrinsic MICs, neither CFZ nor OXA had effect against the four strains in the SEV model at human-equivalent, pharmacokinetic-based simulated dose-regimens. The activity curves among the strains were indistinguishable regardless of clonal background at all time points (Figures 1; 2) as well as for the overall exposure based on similar AUBC values (Table 3). Based on the MICs determined in CAMHB, OXA achieved zero percent $f \mathrm{~T}>\mathrm{MIC}$ for all strains, while CFZ achieved zero percent $f \mathrm{~T}>\mathrm{MIC}$ for $\mathrm{COL}$ and $\mathrm{BMC}-1001$ and $33 \%$ and $57 \% f \mathrm{~T}>\mathrm{MIC}$ for $11-11$ and MW2, respectively.

- Bicarbonate supplementation of $C A M H B$ in the central compartment resulted in significant CFZ or OXA bactericidal activity in responsive (but not in non-responsive) MRSA strains in the ex vivo SEV model. Figure 1 displays the pharmacodynamic SEV kill curve of CFZ against all four strains with and without $\mathrm{NaHCO}_{3}$ supplementation. Based on MIC reductions noted in strains 11-11 and MW2 in this study, as well as in our previous in vitro work (14), we predicted that CFZ and OXA would each yield substantial intra-SEV antimicrobial 
152 activity against these responsive strains in the presence of $\mathrm{NaHCO}_{3}$ supplementation.

153 Accordingly, in the ex vivo SEV model supplemented with $\mathrm{NaHCO}_{3}, \mathrm{CFZ}$ and OXA resulted in

154 significantly greater anti-MRSA activity as compared to standard CAMHB medium in these

155 responsive strains. After $8 \mathrm{hrs}$ in the SEV model, $\beta$-lactam exposures in bicarbonate-

156 supplemented media resulted in significantly greater activity as compared to standard CAMHB

157 media (Figure 1, $\mathrm{P}<0.05$ for timepoints 8-72 hrs). In comparing ex vivo kill curves between the

158 different $\mathrm{NaHCO}_{3}$ concentrations, $\beta$-lactam exposure of the "responsive strains" in CAMHB

159 medium supplemented with $44 \mathrm{mM} \mathrm{NaHCO}_{3}$ yielded a significantly greater bacterial count

160 reduction for both $\mathrm{CFZ}$ and $\mathrm{OXA}$ vs $25 \mathrm{mM} \mathrm{NaHCO}_{3}$ supplementation at most time points from

$161 \quad 24-72$ hrs (Figure 1 and Figure 2, $\mathrm{P}<0.05)$. In contrast, there was no difference in killing of the

162 nonresponsive strains, $\mathrm{COL}$ and $\mathrm{BMC}-1001$, with $\mathrm{NaHCO}_{3}$ supplementation (vs either antibiotic-

containing standard CAMHB medium or in untreated growth controls).

Overall, there was a notable $\mathrm{NaHCO}_{3}$-concentration response, with higher bacterial count reductions, faster time to bactericidal activity (time to $3 \log _{10}$ CFU/g reduction), and lower respectively, with $25 \mathrm{mM} \mathrm{NaHCO}_{3}$ for these strains. Since no change in MIC occurred in $\mathrm{CAMHB}+\mathrm{NaHCO}_{3}$ in the nonresponsive strains, the $f \mathrm{~T}>\mathrm{MIC}$ remained at zero percent, and 172 reflects the lack of any $\beta$-lactam activity against those strains.

- $\quad$ CFZ and OXA are each bactericidal ex vivo against $\mathrm{NaHCO}_{3}$-responsive (but not

175 against non-responsive) MRSA in the host-mimicking medium, RPMI. As noted above, CFZ and 176 OXA MICs for all four strains were substantially reduced in RPMI. We next determined if these 177 , in vitro outcomes were mirrored ex vivo in the SEV model. As displayed in Figure 3, the 
$178 \mathrm{NaHCO}_{3}$-responsive strains, 11-11 and $\mathrm{MW}$, were significantly killed with CFZ or OXA

179 treatment in this medium; this is reflected in the enhanced pharmacodynamic attainment in this

180 medium, resulting in $100 \% f \mathrm{~T}>\mathrm{MIC}$ for CFZ and $60 \%$ for OXA against both $11-11$ and MW2

181 strains. In contrast, over the same $72 \mathrm{hrs} \beta$-lactam exposure period, the two nonresponsive

182 strains (COL and BMC-1001) were minimally affected by either agent. It should be noted that

183 there was initial activity with CFZ against COL in RPMI, with 2 $\log _{10}$ CFU/g killing at 24-48 hrs.

184 However, this was not sustained after 48 hours, and the strain regrew to the initial inoculum.

185 These data are reflected in the lower target attainment of $8.2 \%-56 \% f \mathrm{~T}>\mathrm{MIC}$ for CFZ and $0 \%-$

$18620 \%$ for $f \mathrm{~T}>\mathrm{MIC}$ for OXA.

187

- $\quad \beta$-lactam treatment did not select for high-level CFZ or OXA resistance 


\section{DISCUSSION}

The $\beta$-lactam class of antibiotics remains the treatment of choice for a broad range of susceptible pathogens due to their potent and rapid mechanism(s) of action, as well as their relatively low rates of adverse side effects and toxicities. In addition, they have recently become well-characterized as able to augment the innate host immune system, via their synergistic

210 interactions with host defense peptides against key gram-positive pathogens, including $S$. 211 aureus (19-21). of standard MRSA in vitro media to identify a sub-set of MRSA strains that may, in fact, exhibit $\beta$-lactam susceptibility $(14,22,23)$. The notion of employing alternative media for antibiotic susceptibility screening is not new; however, the biological basis and clinical utility of this

217 approach has substantially increased in the last few years. For example, Kubicek-Sutherland et al mimicked the intracellular conditions of the macrophage phagosome in which Salmonella resides, using a mildly acidic and phosphate/magnesium-poor culture medium. Their study revealed that when Salmonella were grown in this media, antimicrobial susceptibility profiles emerging from this scenario were better predictors of treatment outcomes in murine bacteremia 222 models than more traditional susceptibility testing strategies (23). Similar studies using Acinetobacter and staphylococci grown in Dulbecco Modified Eagles Medium (DMEM) or RPMI were better predictors of in vivo treatment outcomes, when compared to standard susceptibility 225 testing modalities $(13,15)$. It should be emphasized that all four of our prototype MRSA isolates 226 were rendered significantly more $\beta$-lactam-susceptible in vitro in RPMI media (4- to 64-fold MIC 227 reductions). However, these salutary in vitro results in RPMI did not accurately predict 228 subsequent microbiologic outcomes in the SEV model. 
The enhanced antimicrobial activity seen above in such alternative media, as well as

231

232

233

234

235

236

237

238

239

240

241

242

243

244

245

246

247

248

249

250

251

252

253

254

255

The treatment of MRSA infections poses several daunting challenges. Current treatment options for MRSA infections are relatively limited, and include antibiotics that are not only costly, but also substantially less effective, and often more toxic when compared to standard antibiotic treatments for MSSA (25-27). This is in large part due to the perceived inability to use traditional $\beta$-lactam antibiotics for MRSA infections (6). The mecA gene is primarily responsible for mediating $S$. aureus resistance to traditional $\beta$-lactams, encoding for penicillin-binding protein 2A (PBP2A), which has low affinity to most standard-of-care antistaphylococcal $\beta$-lactam antibiotics (6). Despite this, combination therapy featuring $\beta$ lactams plus anti-MRSA agents such as vancomycin and daptomycin have proven to be effective in selected patients with recalcitrant MRSA infections (19, 28-30). In addition, many MRSA strains which exhibit reduced susceptibility to vancomycin and daptomycin often demonstrate a paradoxical increase in susceptibility to $\beta$-lactams, a phenomenon known as the "see-saw effect"; this provides an additional scenario in which $\beta$-lactam agents may provide synergistic efficacy for MRSA killing (19). 
256

257

258

259

260

261

262

263

264

265

266

267

268

269

270

271

272

273

274

275

276

277

278

279

280

281

collection of well-characterized MRSA strains $(n=58)$ for this same phenotype. We identified that three-quarters of this cohort were CFZ-susceptible in $\mathrm{NaHCO}_{3}$-supplemented $\mathrm{CA}-\mathrm{MHB}$, while one-third were OXA-susceptible in the same media (31). We have investigated the potential mechanisms by which $\mathrm{NaHCO}_{3}$ may cause such $\beta$-lactam hypersusceptibility in vitro and demonstrated that $\mathrm{NaHCO}_{3}$-supplemented media can down-regulate expression of the mecA gene, and subsequent PBP2a production, as well as by impacting several genes involved in maintenance of the MRSA phenotype, including sarA and blaZ(14).

The pharmacodynamic parameter best correlated with efficacy of $\beta$-lactam antibiotics is $f \mathrm{~T}>\mathrm{MIC}$ (time-above-MIC of the free drug); this metric has been highly studied in vivo and in vitro, and is validated to predict improved clinical outcomes in $\beta$-lactam-treated patients (32-35). In most investigations, $\beta$-lactams demonstrate optimal activity with $f \mathrm{~T}>\mathrm{MIC}$ in the range of 40 $60 \%$ (32). Relevant to our study, we found that the lower MICs observed in $\mathrm{NaHCO}_{3}^{-}$ supplemented media for two of our prototype strains (11-11 and MW2) resulted in an "MSSAlike phenotype" improving the potential for target attainment for both CFZ and OXA. For the $\mathrm{NaHCO}_{3}$-responsive strains, CFZ achieved at least $83 \% f \mathrm{~T}>\mathrm{MIC}$, resulting in a substantial and durable bactericidal activity in the ex vivo SEV model. Similarly, OXA, with a calculated $\sim 60 \%$ $f \mathrm{~T}>\mathrm{MIC}$ in the two $\mathrm{NaHCO}_{3}$-responsive strains, also achieved good bactericidal activity in the ex vivo model.

The ex vivo simulated endocardial vegetation (SEV) model has been extensively used to pharmacokinetically and pharmacodynamically study the impacts of many antimicrobials against several clinical bacterial isolates in order to verify these interactions in a setting more akin to the host tissue microenvironment than in vitro assays $(36,37)$. In addition, this model has been shown to successfully recapitulate the microbiologic results generated in several in vivo animal models, including rabbit endocarditis (IE) (38). In the present investigation, we used this same 
282

283

284

285

286

287

288

289

290

291

292

293

294

295

296

297

298

299

300

301

302

303

304

305

306

ex vivo pharmacokinetic-pharmacodynamic model to more systematically evaluate the activity of CFZ and OXA against our four prototype MRSA isolates, in a host-mimicking microenvironment. Our current results in the SEV model provided an important "bridge" between in vitro and in vivo outcomes with these strains. First, the two MRSA that were significantly $\beta$-lactam $/ \mathrm{NaHCO}_{3}$ responsive in vitro and in vivo (14), showed enhanced intra-SEV killing by CFZ and OXA in the presence of $\mathrm{NaHCO}_{3}$. In parallel, the two $\beta$-lactam $/ \mathrm{NaHCO}_{3}$-nonresponsive strains (as defined in vitro and in vivo) were not substantially killed by CFZ or OXA ex vivo. Second, as seen in vitro, there appeared to be a $\mathrm{NaHCO}_{3}$ concentration-optimum for the $\beta$-lactam $/ \mathrm{NaHCO}_{3}$ sensitizing phenotype for the two responsive strains (11-11 and MW2); thus, significant killing was seen ex vivo within SEVs both at 25 and $44 \mathrm{mM}$, but with a substantially greater bactericidal effect seen at the latter concentration. In contrast, the excellent in vivo clearance of both $\mathrm{NaHCO}_{3}$-responsive MRSA which occurs in vivo at $\mathrm{NaHCO}_{3}$ concentrations of $20-25 \mathrm{mM}$ (14) suggests that additional host factors within cardiac vegetations or other target organs are in-play to synergistically kill MRSA [e.g., PMNs; platelets, host defense peptides; antibody, etc. $(13-15)]$.

There remains a current debate over the most appropriate $\beta$-lactam to treat serious MSSA infections, with CFZ or OXA as the primary candidates $(25,39)$; most recent MSSA bacteremia studies appear to favor $\operatorname{CFZ}(16,26,27)$. Further, on balancing adverse events vs efficacy metrics, CFZ is generally regarded as a safer option, due to its decreased renal toxicity risk as compared to the antistaphylococcal penicillins $(16,27)$. However, there remains concern about CFZ efficacy in "high-inoculum" $S$. aureus infections (e.g., endocarditis) due to the potential for the undetected presence and induction of genes for Types A or C cephalosporinases that hydrolyze CFZ $(39,40)$. In our current study, CFZ appeared to be unaffected by the high inoculum within SEVs, at least for the $\mathrm{NaHCO}_{3}$-responsive strains, 11-11 
307

308

309

310

and MW2, with excellent CFZ bactericidal activity obtained despite starting inocula $\geq 1 \times 10^{8}$ CFU/g.

In conclusion, this study further validates the potential clinical translatability of the intriguing finding of $\beta$-lactam $/ \mathrm{NaHCO}_{3}$ sensitization of selected MRSA strains in vitro. It will be important to extend our studies to even larger clinical MRSA cohorts (31). Ultimately, a pivotal clinical trial will be required to fully adjudicate the clinical utility of defining MRSA strains as $\beta$-lactam/ $\mathrm{NaHCO}_{3}$-responsive in the clinical microbiology laboratory.

ACKNOWLEDGEMENTS. This study was supported in part by a research grant from the National Institutes of Health (NIAID 1R01Al146078-01) to A.S.B. and (NIAID 1RO1Al13262702) to W.E.R.

\section{MATERIALS AND METHODS}

Bacterial strains, media and antibiotics. The strains used in this study were all clinical MRSA isolates, and represent diverse contemporary clonal genotypes (USA types) found worldwide in MRSA infections. These included MRSA 11/11 (USA300), MW2 (USA400), COL (USA100), and BMC-1001 (USA500). These strains are well-described in the literature and were recently utilized to define $\mathrm{NaHCO}_{3}$-responsivity in vitro (14). All strains were stored at $-80^{\circ} \mathrm{C}$ in tryptic soy broth with $15 \%$ glycerol until thawed for use. Bacteria were cultured on MHA and incubated at $37^{\circ} \mathrm{C}$ in ambient air. Five liquid culture media were used for susceptibility testing comparisons including i) cation-adjusted Mueller Hinton Broth (CAMHB, Difco) with the addition of $100 \mathrm{mM}$ Tris (hydroxymethyl-aminomethane; Fisher Scientific) to maintain $\mathrm{pH}$ at 
approximately $7.3 \pm 0.1$, ii) CAMHB-Tris supplemented with $2 \% \mathrm{NaCl}$; iii) CAMHB-Tris-NaCl supplemented with $25 \mathrm{mM} \mathrm{NaHCO}_{3}$; iv) CAMHB-Tris-NaCl supplemented with $44 \mathrm{mM} \mathrm{NaHCO}_{3}$; or iv) tissue culture medium, Roswell Park Memorial Institute (RPMI) 1640 (Fisher Scientific) supplemented with 10\% Luria-Bertani (LB) broth; this latter medium contains $~ 25 \mathrm{mM} \mathrm{NaHCO}_{3}$, as well as biotin, vitamin $\mathrm{B}_{12}$, and PABA, and in addition, the vitamins, inositol and choline. Media types ii-v were used for the ex vivo SEV model. The $\beta$-lactam antibiotics, OXA and CFZ, were purchased as analytical powders from Sigma-Aldrich (St. Louis, MO), and prepared fresh prior to each experiment according to the manufacturer's protocols.

Antibiotic susceptibility assays. CLSI guidelines (11) for microbroth dilution were used to determine antibiotic susceptibility (MICs) with modifications to the recommended media (12). Bacteria were grown overnight at $35^{\circ} \mathrm{C}$ on $\mathrm{MHA}$, and resulting colonies were suspended in the different media listed above to the equivalent of 0.5 McFarland standard. This was further diluted 1:100 for a final inoculum of $5 \times 10^{5} \mathrm{CFU} / \mathrm{ml}$. Antibiotics were serially diluted 2-fold, and MICs were defined by standard metrics (11) and determined in triplicate on two separate days ( $n=6$ replicates $)$.

\section{Pharmacodynamic model with ex vivo simulated endocardial vegetations (SEVs). Each} organism inoculum was prepared by spreading 0.5 McFarland standard on three MHA plates and incubating for 18-24 hrs. Bacteria were collected by scraping plates, and then adding to 5 $\mathrm{ml} \mathrm{CA-MHB}$ in suspension. SEVs were prepared in $1.5 \mathrm{ml}$ microcentrifuge tubes by mixing 50 $\mu \mathrm{L}$ of this organism suspension (final inoculum, $10^{8} \mathrm{CFU} / \mathrm{g}$ ) with $0.5 \mathrm{ml}$ of pooled human cryoprecipitate antihemophilic factor prepared from plasma (fibrinogen, von Willebrand factor, factor VIII, factor XIII and fibronectin) and 250,000 to 500,000 pooled platelets from human volunteer donors (UW Health Blood Bank, Madison, WI). These components were lightly vortexed, and a monofilament line added to each mixture along with $0.05 \mathrm{ml}$ Bovine thrombin 
(5,000 units/ml). After gentle stirring, the resulting SEVs were removed from the tubes and then suspended within the central 'fluid phase' of this model. This preparation results in SEVs weighing $\sim 0.7 \mathrm{~g}$ and containing 3-3.5 $\mathrm{g} / \mathrm{dL}$ of albumin and 6.8-7.4 g/dL of total protein (equating to human physiologic levels). The protein binding of the study drugs has been found to be $84 \%$ for CFZ and $92 \%$ for OXA, which was used to calculate free AUC ( $f A U C$ ) and percent time of

364 free drug above the MIC (\%fT>MIC) $(41,42)$.

The central ('fluid') compartment model for the SEVs consists of a $150 \mathrm{ml}$ flask glass with sealed screw cap. The flask was prefilled with media and magnetic stir bar, and SEVs were added for 30 minutes prior to antibiotic dosing to allow for climate acclimation. The model was maintained at $35-37^{\circ} \mathrm{C}$ ambient air and fresh media instilled via a continuous syringe pump system (New Era Pump Systems, Inc.) to provide a human pharmacokinetic simulation of the antibiotics. All model experiments were performed in duplicate flasks to ensure reproducibility with two SEVs collected for each time point ( $n=4$ SEVs per time point).

- Simulated antimicrobial regimens. All regimens were derived from human pharmacokinetic data and standard dosing regimens for humans with MSSA infections

375 previously published: OXA = 2 grams infused every 6 hrs (43) or CFZ = 2 grams infused every 8 376 hrs $(43,44)$. Antibiotics were administered as boluses over 1 minute into a luer-lock port of the 377 flask at the scheduled administration time, over $72 \mathrm{hrs}$ dosing duration. The predicted pharmacokinetics of each regimen are provided in Table 2.

Pharmacokinetic analysis and exposure determination. Pharmacokinetic samples were obtained in duplicate through the injection port of each model from 0-72 hrs for verification of target antibiotic concentration attainment. All samples were stored at $-80^{\circ} \mathrm{C}$ until ready for analysis. Concentrations of OXA were determined by bioassay using Kocuria rhizophila ATCC 9341 on MHA as previously described (44). Concentrations of CFZ were determined by 
bioassay using test organism Bacillus subtilis ATCC 6633 on MHA (45). The half-lives, areaunder-the-curve 0-24 hrs (AUC), maximum and minimum concentrations $\left(C_{\max }, C_{\min }\right)$ of each

387 antibiotic were determined by the trapezoidal method utilizing Prism (GraphPad Software, Inc.).

388 Observed $f$ AUC/MIC and $\% f$ T $>$ MIC were determined in Prism and reported for OXA and CFZ.

Assessment for emergence of variants with high-level $\beta$-lactam resistance in the ex vivo

model. Samples of $100 \mu \mathrm{l}$ from each time-point were parallel-plated onto MHA plates containing either no antibiotic or 4-fold the respective $\beta$-lactam initial MICs to assess for the emergence of high-level resistant mutants. Plates were then examined for growth after $48 \mathrm{hrs}$ incubation at $35^{\circ} \mathrm{C}$. Specific CFZ or OXA MICs were then performed on selected colonies exhibiting growth the 72 hrs $\beta$-lactam exposure period.

Statistical analysis. Bacterial counts, expressed as $\log _{10} \mathrm{CFU} / \mathrm{g}$, in SEVs at each time point were determined for each antibiotic treatment and growth condition for each strain. AUBC, 400 defined as area under the bacterial growth curves (AUBC) over the $72 \mathrm{~h}$ experiments, was also 401 calculated. A two-way analysis of variance was used with Tukey's Post-Hoc test to compare 402 bacterial counts and AUBC with a $P$ value of $\leq 0.05$ for significance. All statistical comparisons 403 were analyzed using Prism 8 (GraphPad Software, San Diego, CA). 
407

408

409

410

411

412

413

414

415

416

417

418

419

420

421

422

423

424

425

426

427

428

429

430

\section{REFERENCES}

1. Lowy FD. 1998. Staphylococcus aureus infections. N Engl J Med 339: 520-532.

2. Weiner LM, Webb AK, Limbago B, Dudeck MA, Patel J, Kallen AJ, Edwards JR, Sievert DM. 2016. Antimicrobial-resistant pathogens associated with healthcare-associated infections: summary of data reported to the national healthcare safety network at the centers for disease control and prevention, 2011-2014. Infect Control Hosp Epidemiol 37: 1288-1301.

3. Lee AS, de Lencastre H, Garau J, Kluytmans J, Malhotra-Kumar S, Peschel A, Harbarth S. 2018. Methicillin-resistant Staphylococcus aureus. Nat Rev Dis Primers 4: 1803.

4. Tong SY, Davis JS, Eichenberger E, Holland TL, Fowler VG, Jr. 2015. Staphylococcus aureus infections: epidemiology, pathophysiology, clinical manifestations, and management. Clin Microbiol Rev 28: 603-61.

5. Centers for Disease Control and Prevention. 2013. Antibiotic Resistance Threats in the United States. http://www.cdc.gov/drugresistance/threat-report-2013/. Accessed 8/13/2016.

6. Turner NA, Sharma-Kuinkel BK, Maskarinec SA, Eichenberger EM, Shah PP, Carugati M, Holland TL, Fowler VG, Jr. 2019. Methicillin-resistant Staphylococcus aureus: an overview of basic and clinical research. Nat Rev Microbiol 17: 203-218.

7. Bayer AS, Mishra NN, Chen L, Kreiswirth BN, Rubio A, Yang SJ. 2015. Frequency and distribution of single-nucleotide polymorphisms within mprf in methicillin-resistant Staphylococcus aureus clinical isolates and their role in cross-resistance to daptomycin and host defense antimicrobial peptides. Antimicrob Agents Chemother 59: 4930-7. 
431 8. Lee H, Yoon EJ, Kim D, Kim JW, Lee KJ, Kim HS, Kim YR, Shin JH, Shin JH, Shin KS, Kim YA, Uh Y, Jeong SH. 2018. Ceftaroline resistance by clone-specific polymorphism in penicillin-binding protein 2a of methicillin-resistant Staphylococcus aureus. Antimicrob Agents Chemother 62: pii: e00485-18.

9. Kullar R, Sakoulas G, Deresinski S, van Hal SJ. 2016. When sepsis persists: a review of MRSA bacteraemia salvage therapy. J Antimicrob Chemother 71:576-86.

10. Projan SJ, Shlaes DM. 2004. Antibacterial drug discovery: is it all downhill from here? Clin Microbiol Infect 10 Suppl 4: 18-22.

11. Clinical and Laboratory Standards Institute. 2015. Methods for antimicrobial dilution antimicrobial susceptibilty tests for bacteria that grow aerobically; approved standard-

443 12. Clinical and Laboratory Standards Institute. 2019. Performance standards for tenth ed, CLSI document M07-A10. Clinical and Laboratory Standards Institute, Wayne, antimicrobial susceptibility testing. CLSI document M100-ED29; Clinical and Laboratory Standards Institute, Wayne, PA. Susceptibility Testing. EBioMedicine 20: 173-181.

14. Ersoy SC, Abdelhady W, Li L, Chambers HF, Xiong YQ, Bayer AS. 2019. Bicarbonate Jr., Corriden R, Rohde M, Hensler ME, Burkart MD, Pogliano J, Sakoulas G, Nizet V. resensitization of methicillin-resistant Staphylococcus aureus to $\beta$-lactam antibiotics. Antimicrob Agents Chemother 63: pii: e00496-19. 2015. Azithromycin synergizes with cationic antimicrobial peptides to exert bactericidal and therapeutic activity against highly multidrug-resistant gram-negative bacterial pathogens. EBioMedicine 2: 690-8. 
16. Bidell MR, Patel N, O'Donnell JN. 2018. Optimal treatment of MSSA bacteraemias: a meta-analysis of cefazolin versus antistaphylococcal penicillins. J Antimicrob Chemother 73: $2643-2651$.

17. Tong SY, Nelson J, Paterson DL, Fowler VG, Jr., Howden BP, Cheng AC, Chatfield M, Lipman J, Van Hal S, O'Sullivan M, Robinson JO, Yahav D, Lye D, Davis JS, group Cs, the Australasian Society for Infectious Diseases Clinical Research N. 2016. CAMERA2 combination antibiotic therapy for methicillin-resistant Staphylococcus aureus infection: study protocol for a randomised controlled trial. Trials 17: 170.

18. Volk CF, Burgdorf S, Edwardson G, Nizet V, Sakoulas G, Rose WE. 2019. IL-1beta and ILI-10 host responses in patients with Staphylococcus aureus bacteremia determined by antimicrobial therapy. Clin Infect Dis in press.

19. Dhand A, Bayer AS, Pogliano J, Yang SJ, Bolaris M, Nizet V, Wang G, Sakoulas G. 2011. Use of antistaphylococcal beta-lactams to increase daptomycin activity in eradicating persistent bacteremia due to methicillin-resistant Staphylococcus aureus: role of enhanced daptomycin binding. Clin Infect Dis 53:158-63.

20. Sakoulas G, Okumura CY, Thienphrapa W, Olson J, Nonejuie P, Dam Q, Dhand A, Pogliano J, Yeaman MR, Hensler ME, Bayer AS, Nizet V. 2014. Nafcillin enhances innate immune-mediated killing of methicillin-resistant Staphylococcus aureus. J Mol Med 92: 139-49.

21. Rose WE, Leonard SN, Rybak MJ. 2008. Evaluation of daptomycin pharmacodynamics and resistance at various dosage regimens against Staphylococcus aureus isolates with reduced susceptibilities to daptomycin in an in vitro pharmacodynamic model with simulated endocardial vegetations. Antimicrob Agents Chemother 52: 3061-7.

22. Ribeiro LS, Migliari Branco L, Franklin BS. 2019. Regulation of innate immune responses by platelets. Front Immunol 10: 1320 . 
23. Kubicek-Sutherland JZ, Heithoff DM, Ersoy SC, Shimp WR, House JK, Marth JD, Smith JW, Mahan MJ. 2015. Host-dependent induction of transient antibiotic resistance: a prelude to treatment failure. EBioMedicine 2: 1169-1178.

24. Mueller EA, Egan AJ, Breukink E, Vollmer W, Levin PA. 2019. Plasticity of Escherichia coli cell wall metabolism promotes fitness and antibiotic resistance across environmental conditions. Elife 8: pii: e40754.

25. McDanel JS, Roghmann MC, Perencevich EN, Ohl ME, Goto M, Livorsi DJ, Jones M, Albertson JP, Nair R, O'Shea AMJ, Schweizer ML. 2017. Comparative effectiveness of cefazolin versus nafcillin or oxacillin for treatment of methicillin-susceptible Staphylococcus aureus infections complicated by bacteremia: a nationwide cohort study. Clin Infect Dis 65: 100-106.

26. Burrelli CC, Broadbent EK, Margulis A, Snyder GM, Gold HS, McCoy C, Mahoney MV, Hirsch EB. 2018. Does the beta-lactam matter? Nafcillin versus cefazolin for methicillinsusceptible Staphylococcus aureus bloodstream infections. Chemotherapy 63: 345-351.

27. Pollett S, Baxi SM, Rutherford GW, Doernberg SB, Bacchetti P, Chambers HF. 2016. Cefazolin versus nafcillin for methicillin-sensitive Staphylococcus aureus bloodstream infection in a California tertiary medical center. Antimicrob Agents Chemother 60: 46849.

28. Jorgensen SCJ, Zasowski EJ, Trinh TD, Lagnf AM, Bhatia S, Sabagha N, AbdulMutakabbir JC, Alosaimy S, Mynatt RP, Davis SL, Rybak MJ. 2019. Daptomycin plus beta-lactam combination therapy for methicillin-resistant Staphylococcus aureus bloodstream infections: a retrospective, comparative cohort study. Clin Infect Dis in press.

29. Casapao AM, Jacobs DM, Bowers DR, Beyda ND, Dilworth TJ. 2017. Early administration of adjuvant beta-lactam therapy in combination with vancomycin among 
patients with methicillin-resistant Staphylococcus aureus bloodstream infection: a retrospective, multicenter analysis. Pharmacotherapy 37: 1347-1356.

509

30. Sakoulas G, Moise PA, Casapao AM, Nonejuie P, Olson J, Okumura CY, Rybak MJ, Kullar R, Dhand A, Rose WE, Goff DA, Bressler AM, Lee Y, Pogliano J, Johns S, Kaatz GW, Ebright JR, Nizet V. 2014. Antimicrobial salvage therapy for persistent staphylococcal bacteremia using daptomycin plus ceftaroline. Clin Ther 36: 1317-3.

31. Ersoy SC, Zapata-Davila B, Otmishi M, Milan V, Li L, Chambers HF, Xiong YQ, Bayer AS. 2019 Abstr IDWeek, abstr 607. Scope and predictive genetic/phenotypic signatures of 'bicarbonate-responsivity' and $\beta$-lactam sensitization among methicillin-resistant Staphylococcus aureus.

32. Lodise TP, Lomaestro BM, Drusano GL, Society of Infectious Diseases Pharmacists. 2006. Application of antimicrobial pharmacodynamic concepts into clinical practice: focus on beta-lactam antibiotics: insights from the Society of Infectious Diseases Pharmacists. Pharmacotherapy 26: 1320-32.

33. MacVane SH, Kuti JL, Nicolau DP. 2014. Prolonging beta-lactam infusion: a review of the rationale and evidence, and guidance for implementation. Int J Antimicrob Agents 43: 105-13.

34. Andes D, Craig WA. 2002. Animal model pharmacokinetics and pharmacodynamics: a critical review. Int J Antimicrob Agents 19: 261-8.

35. Craig WA. 1998. Pharmacokinetic/pharmacodynamic parameters: rationale for antibacterial dosing of mice and men. Clin Infect Dis 26: 1-10.

36. Rose WE, Leonard SN, Sakoulas G, Kaatz GW, Zervos MJ, Sheth A, Carpenter CF, Rybak MJ. 2008. Daptomycin activity against Staphylococcus aureus following vancomycin exposure in an in vitro pharmacodynamic model with simulated endocardial vegetations. Antimicrob Agents Chemother 52: 831-836. 
532 37. Rybak MJ, Allen GP, Hershberger E. 2001. In vitro antbiotic pharmacodynamic models, p 41-65. In Nightingale CH, Murakawa T, Ambrose PG (ed), Antimicrobial Pharmacodynamics in Theory and Clinical Practice. Marcell Dekker, Inc, New York.

38. Kebriaei R, Rice SA, Stamper KC, Seepersaud R, Garcia-de-la-Maria C, Mishra NN, Miro JM, Arias CA, Tran TT, Sullam PM, Bayer AS, Rybak MJ. 2019. Daptomycin doseranging evaluation with single-dose versus multidose ceftriaxone combinations against Streptococcus mitis/oralis in an ex vivo simulated endocarditis vegetation model. Antimicrob Agents Chemother 63: pii: e00386-19.

39. Miller WR, Seas C, Carvajal LP, Diaz L, Echeverri AM, Ferro C, Rios R, Porras P, Luna C, Gotuzzo E, Munita JM, Nannini E, Carcamo C, Reyes J, Arias CA. 2018. The cefazolin inoculum effect is associated with increased mortality in methicillin-susceptible Staphylococcus aureus bacteremia. Open Forum Infect Dis 5:ofy123.

40. Miller WR, Singh KV, Arias CA, Murray BE. 2018. Adjunctive clavulanic acid abolishes the cefazolin inoculum effect in an experimental rat model of methicillin-sensitive Staphylococcus aureus endocarditis. Antimicrob Agents Chemother 62. pii: e01158-18.

41. Standiford HC, Jordan MC, Kirby WM. 1970. Clinical pharmacology of carbenicillin compared with other penicillins. J Infect Dis 122: Suppl:S9-13.

42. Smyth RD, Pfeffer M, Glick A, Van Harken DR, Hottendorf GH. 1979. Clinical pharmacokinetics and safety of high doses of ceforanide (BL-S786R) and cefazolin. Antimicrob Agents Chemother 16: 615-21.

43. Hagihara M, Wiskirchen DE, Kuti JL, Nicolau DP. 2012. In vitro pharmacodynamics of vancomycin and cefazolin alone and in combination against methicillin-resistant Staphylococcus aureus. Antimicrob Agents Chemother 56: 202-7.

44. LaPlante KL, Rybak MJ. 2004. Impact of high-inoculum Staphylococcus aureus on the activities of nafcillin, vancomycin, linezolid, and daptomycin, alone and in combination 
bioRxiv preprint doi: https://doi.org/10.1101/807255; this version posted October 16,2019 . The copyright holder for this preprint (which was not certified by peer review) is the author/funder, who has granted bioRxiv a license to display the preprint in perpetuity. It is made available under aCC-BY 4.0 International license.

with gentamicin, in an in vitro pharmacodynamic model. Antimicrob Agents Chemother

48: 4665-72.

559 45. Fields MT, Herndon BL, Bamberger DM. 1993. Beta-lactamase-mediated inactivation and efficacy of cefazolin and cefmetazole in Staphylococcus aureus abscesses. 
Table 1. Cefazolin and oxacillin MICs in standard and alternative media types used in the pharmacodynamic model

\begin{tabular}{|c|c|c|c|c|c|c|c|c|}
\hline \multirow[b]{2}{*}{ Media } & \multicolumn{4}{|c|}{ CFZ (mg/L) } & \multicolumn{4}{|c|}{ OXA (mg/L) } \\
\hline & 11-11 & MW2 & COL & BMC-1001 & 11-11 & MW2 & COL & BMC-1001 \\
\hline CAMHB-Tris $^{a}$ & 16 & 8 & 256 & 256 & 64 & 32 & 512 & 256 \\
\hline CAMHB-Tris $+2 \% \mathrm{NaCl}$ & 16 & 8 & 256 & 256 & 64 & 32 & 512 & 256 \\
\hline CAMHB-Tris- $\mathrm{NaCl}+25 \mathrm{mM} \mathrm{NAHCO}_{3}$ & 4 & 8 & 256 & 256 & 4 & 32 & 512 & 256 \\
\hline CAMHB-Tris- $\mathrm{NaCl}+44 \mathrm{mM} \mathrm{NAHCO}_{3}$ & 1 & 1 & 256 & 256 & 1 & 2 & 512 & 256 \\
\hline RPMI $1640+10 \%$ LB & 1 & 2 & 32 & 8 & 1 & 1 & 64 & 4 \\
\hline
\end{tabular}

$564{ }^{\mathrm{a} C A M H B}-T$ ris was used only for susceptibility testing and not in the ex vivo SEV model since similar susceptibility in all strains

565 occurred with addition of $2 \% \mathrm{NaCl}$.

566

567

568

569

570 
571 Table 2. Pharmacokinetics of CFZ and OXA in the central compartment (media) of the

572 pharmacodynamic model. Data presented as mean \pm standard error.

\begin{tabular}{|c|c|c|c|c|}
\hline \multirow[b]{2}{*}{ Parameter } & \multicolumn{2}{|c|}{ CFZ 2 g every $8 \mathrm{~h}$} & \multicolumn{2}{|c|}{ OXA 2 g every $6 \mathrm{~h}$} \\
\hline & Predicted & Observed $(n=12)$ & Predicted & Observed $(n=12)$ \\
\hline $\mathrm{C}_{\max }(\mathrm{mg} / \mathrm{L})$ & 256 & $249.4 \pm 2.7$ & 150 & $152.1 \pm 1.4$ \\
\hline $\mathrm{C}_{\min }(\mathrm{mg} / \mathrm{L})$ & 16 & $15 \pm 1$ & 2.3 & $2.2 \pm 0.1$ \\
\hline $\mathrm{k}_{\mathrm{e}}\left(\mathrm{hr}^{-1}\right)$ & 0.385 & $0.354 \pm 0.032$ & 0.693 & $0.705 \pm 0.005$ \\
\hline Half-life (h) & 1.8 & $2.0 \pm 0.2$ & 1 & $1.0 \pm 0.0^{\mathrm{a}}$ \\
\hline $\mathrm{AUC}_{0-24}\left(\mathrm{mg} / \mathrm{L}^{*} \mathrm{~h}\right)$ & 2442 & $2384 \pm 31$ & 1162 & $1217 \pm 91$ \\
\hline
\end{tabular}


575 inversely related to antibiotic activity with lower AUBC indicating greater antibiotic effect. Data represent mean \pm SD of duplicate replicates with two samples taken at each time point $(n=4)$

\begin{tabular}{|c|c|c|c|c|c|}
\hline \multirow[b]{2}{*}{ Regimen } & \multirow[b]{2}{*}{ Media } & \multicolumn{4}{|c|}{ AUBC } \\
\hline & & 11-11 & MW2 & COL & BMC-1001 \\
\hline \multirow[t]{4}{*}{ CFZ } & CAMHB-Tris-NaCl (control) & $626.2 \pm 6.6$ & $658 \pm 3.0$ & $648.4 \pm 2.8$ & $633.9 \pm 4.5$ \\
\hline & CAMHB-Tris- $\mathrm{NaCl}+25 \mathrm{mM} \mathrm{NaHCO}_{3}$ & $455.3 \pm 4.8^{\mathrm{a}}$ & $489.2 \pm 2.5^{\mathrm{a}}$ & $612.1 \pm 2.5$ & $592.7 \pm 3.4$ \\
\hline & CAMHB-Tris- $\mathrm{NaCl}+44 \mathrm{mM} \mathrm{NaHCO}_{3}$ & $310.0 \pm 10.5^{a, b}$ & $390.8 \pm 4.8^{\mathrm{a}, \mathrm{b}}$ & $601.9 \pm 4.5$ & $566.7 \pm 2.9^{a}$ \\
\hline & RPMI $1640+10 \%$ LB & $378.3 \pm 3.5^{\mathrm{a}, \mathrm{b}}$ & $387.3 \pm 6.9^{\mathrm{a}, \mathrm{b}}$ & $505.3 \pm 8.1^{a}$ & $538.8 \pm 6.3^{\mathrm{a}}$ \\
\hline \multirow[t]{4}{*}{ OXA } & CAMHB-Tris- $\mathrm{NaCl}$ & $610 \pm 3.5$ & $661.9 \pm 9.5$ & $621.1 \pm 3.6$ & $642.4 \pm 5.1$ \\
\hline & CAMHB-Tris- $\mathrm{NaCl}+25 \mathrm{mM} \mathrm{NaHCO}_{3}$ & $480 \pm 6.3^{\mathrm{a}}$ & $539.2 \pm 23.3^{\mathrm{a}}$ & $596.7 \pm 6.7$ & $617.3 \pm 2.6$ \\
\hline & CAMHB-Tris- $\mathrm{NaCl}+44 \mathrm{mM} \mathrm{NaHCO}_{3}$ & $392 \pm 17.8^{a, b}$ & $399.4 \pm 15.0^{a, b}$ & $568.9 \pm 11.0^{\mathrm{a}}$ & $603.0 \pm 538$ \\
\hline & RPMI $1640+10 \%$ LB & $415.1 \pm 4.2^{\mathrm{a}, \mathrm{b}}$ & $438.1 \pm 9.3^{\mathrm{a}, \mathrm{b}}$ & $649.7 \pm 4.7$ & $599.1 \pm 9.4$ \\
\hline
\end{tabular}


Figure 1. Kill curve activity of CFZ $2 \mathrm{~g}$ every $8 \mathrm{hrs}$ simulations in the ex vivo SEV model in standard media, CAMHB-Tris- $\mathrm{NaCl}$ (represented as $\mathrm{CAMHB}$ ), and $\mathrm{NaHCO}_{3}$-supplemented CAMHB against MRSA strains 11-11 (A), MW2 (B), COL (C), and BMC-1001 (D). Dashed line is untreated growth in CAMHB, solid lines indicate CFZ regimens. ${ }^{*}=\mathrm{P}<0.05$ vs $\mathrm{CAMHB}$ and $^{* *}=\mathrm{P}<0.05$ vs $\mathrm{CAMHB} 25 \mathrm{mM} \mathrm{NaHCO}_{3}$ media.

Figure 2. Kill curve activity of OXA $2 \mathrm{~g}$ every 6 hrs simulations in the ex vivo SEV model

587 in standard media, CAMHB-Tris- $\mathrm{NaCl}$ (represented as CAMHB), and $\mathrm{NaHCO}_{3^{-}}$ 588 supplemented CAMHB against MRSA strains 11-11 (A), MW2 (B), COL (C), and BMC-1001 589 (D). Dashed line is untreated growth in CAMHB, solid lines indicate OXA regimens. ${ }^{*}=\mathrm{P}<0.05$ 590 vs $\mathrm{CAMHB}$ and ${ }^{* *}=\mathrm{P}<0.05$ vs $\mathrm{CAMHB} 25 \mathrm{mM} \mathrm{NaHCO}_{3}$ media.

Figure 3. Kill curve activity of CFZ $2 \mathrm{~g}$ every 8 hrs and OXA 2 g every 6 hrs simulations in 593 the ex vivo SEV model in host-mimicking RPMI+10\%LB media against MRSA strains 594 11-11 (A), MW2 (B), COL (C), and BMC-1001 (D). * $=P<0.05$ vs control. 
bioRxiv preprint doi: https://doi.org/10.1101/807255; this version posted October 16,2019 . The copyright holder for this preprint (which was not certified by peer review) is the author/funder, who has granted bioRxiv a license to display the preprint in perpetuity. It is made available under A. MRSA 11-11, aCC-BY 4.0 International license.

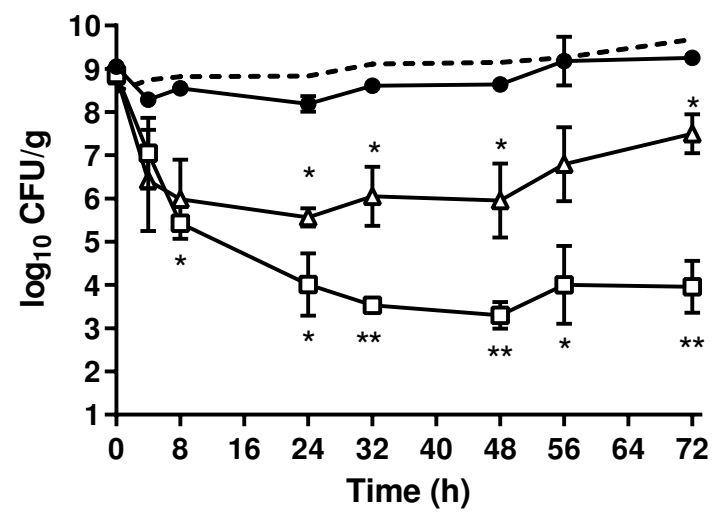

$$
\begin{aligned}
& -\cdots \text { Growth control } \\
& \rightarrow \text { CAMHB } \\
& \triangle \text { CAMHB+25mM NaHCO }_{3} \\
& \curvearrowleft-\text { CAMHB+44mM NaHCO }
\end{aligned}
$$

B. MRSA MW2

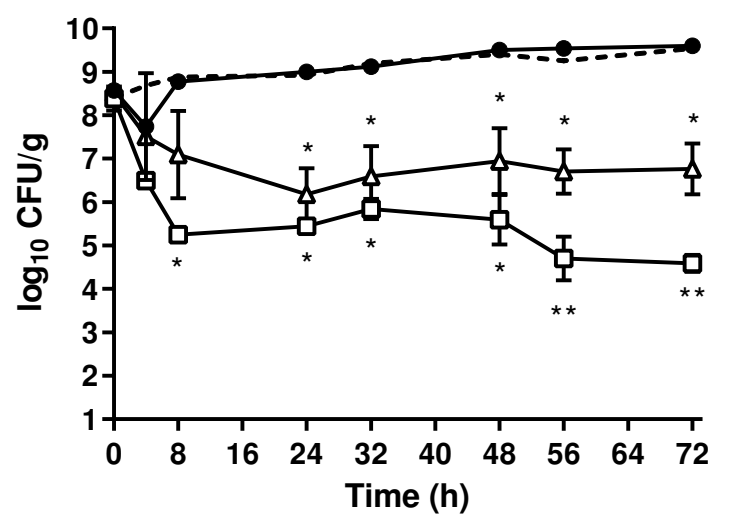

$-\cdots$ Growth control
$\rightarrow$ CAMHB
$-\mathrm{CAMHB}^{-} 25 \mathrm{mM} \mathrm{NaHCO}_{3}$
$-\square \mathrm{CAMHB}+44 \mathrm{mM} \mathrm{NaHCO}_{3}$

C. MRSA COL

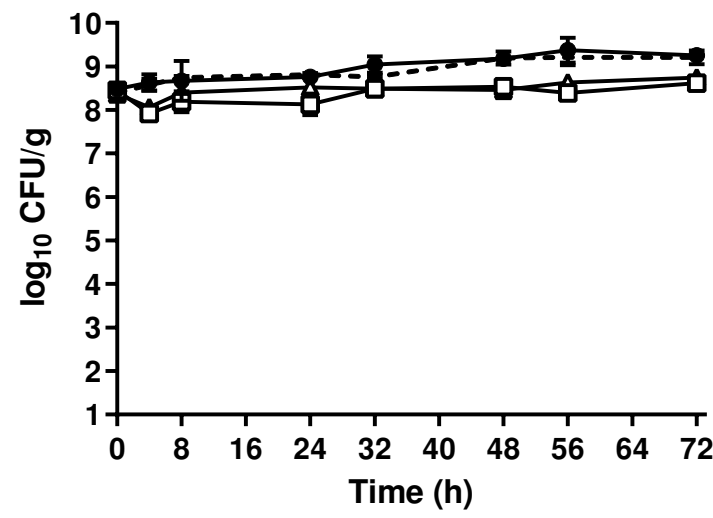

-.. Growth control

$\rightarrow$ CAMHB

$\triangle \quad \mathrm{CAMHB}+25 \mathrm{mM} \mathrm{NaHCO}_{3}$

$\rightarrow$ - $\mathrm{CAMHB}^{4} 44 \mathrm{mM} \mathrm{NaHCO}_{3}$

D. MRSA BMC-1001

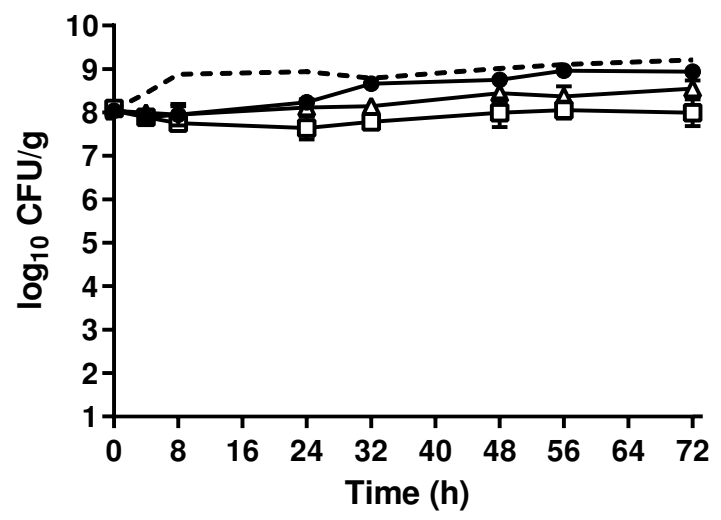


bioRxiv preprint doi: https://doi.org/10.1101/807255; this version posted October 16,2019 . The copyright holder for this preprint (which was not certified by peer review) is the author/funder, who has granted bioRxiv a license to display the preprint in perpetuity. It is made available under A. MRSA 11-11, aCC-BY 4.0 International license.

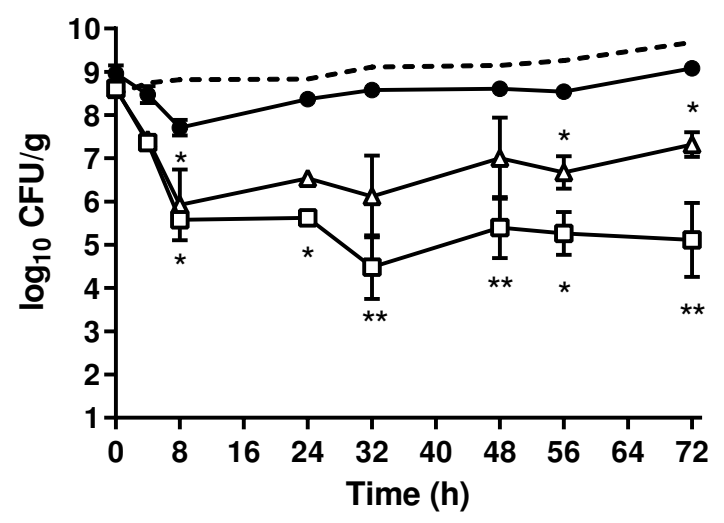

-.. Growth control

$\rightarrow$ CAMHB

$\triangle \mathrm{CAMHB}^{-25 \mathrm{mM} \mathrm{NaHCO}_{3}}$

$\rightarrow-\mathrm{CAMHB}+44 \mathrm{mM} \mathrm{NaHCO}_{3}$

B. MRSA MW2

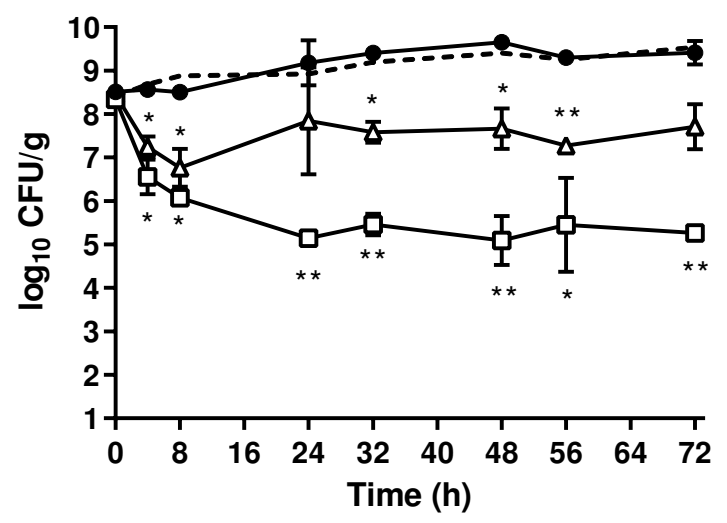

-.. Growth control

$\rightarrow$ CAMHB

$\triangle \mathrm{CAMHB}+25 \mathrm{mM} \mathrm{NaHCO}_{3}$

ㅁ- $\mathrm{CAMHB}^{2} 44 \mathrm{mM} \mathrm{NaHCO}_{3}$

C. MRSA COL

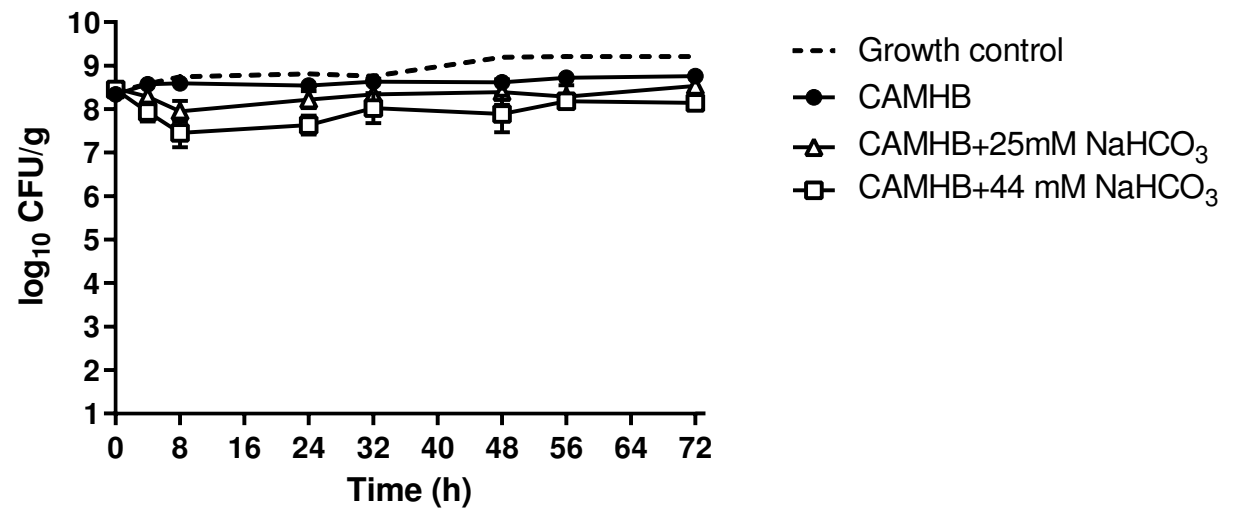

D. MRSA BMC-1001

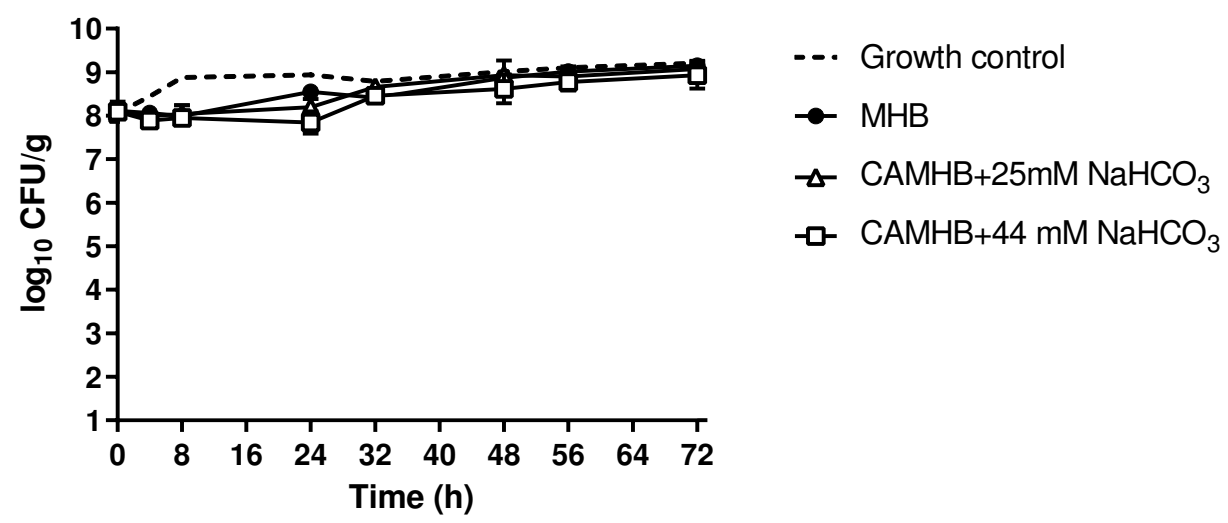


bioRxiv preprint doi: https://doi org/10.1101/807255. this version posted October 16,2019 . The copyright holder for this preprint (which was not certified by peer review) is the author/funder, who has granted bioRxiv a license to display the preprint in perpetuity. It is made available under A. MRSA' 11-11 aCC-BY 4.0 International license.

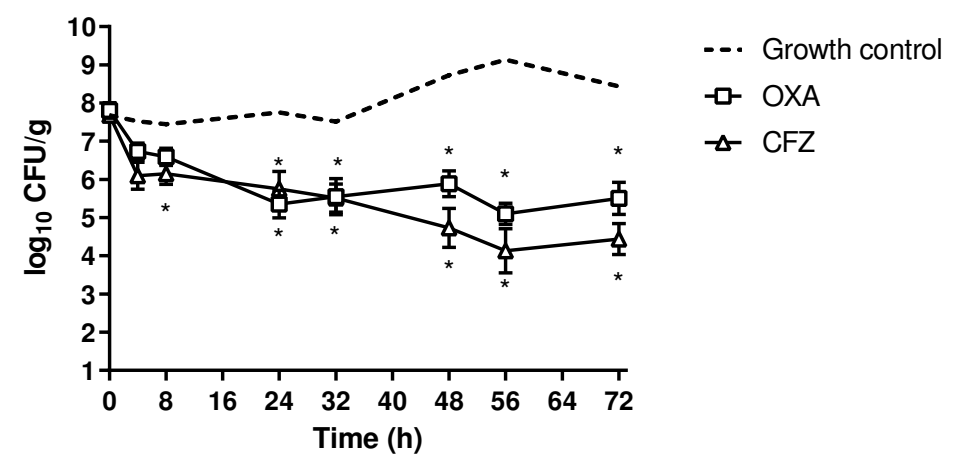

B. MRSA MW2

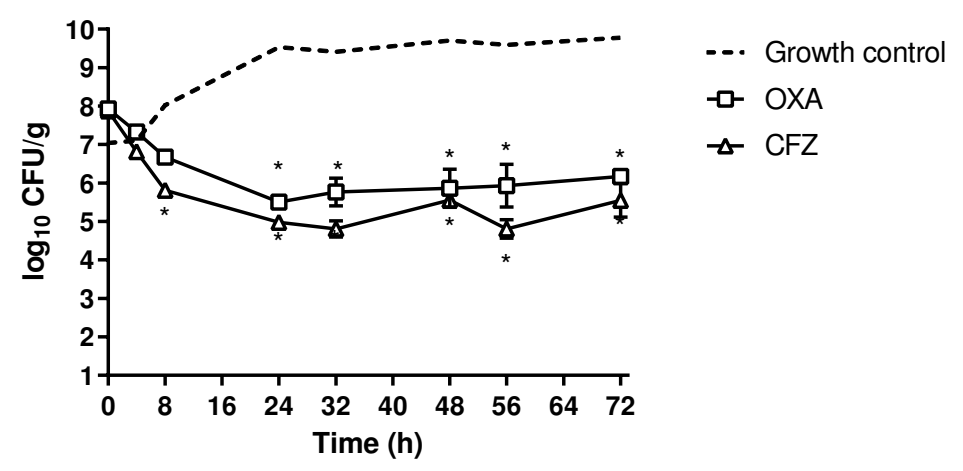

C. MRSA COL

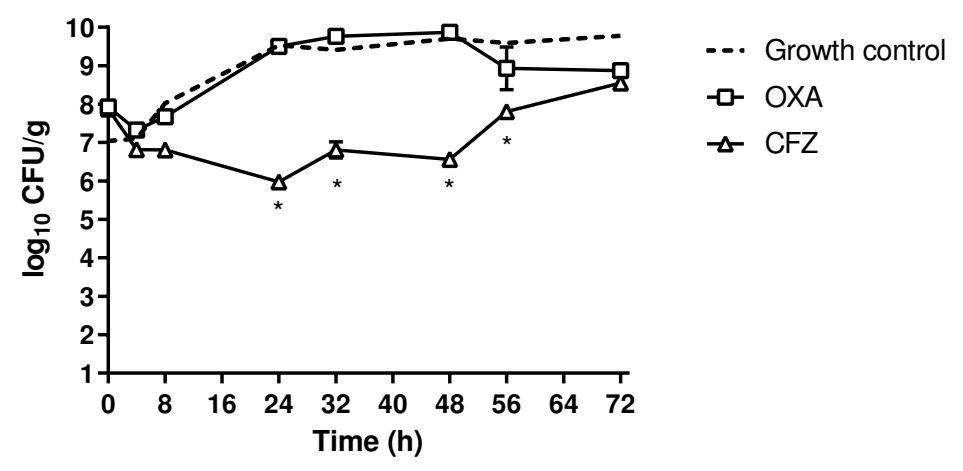

D. MRSA BMC-1001

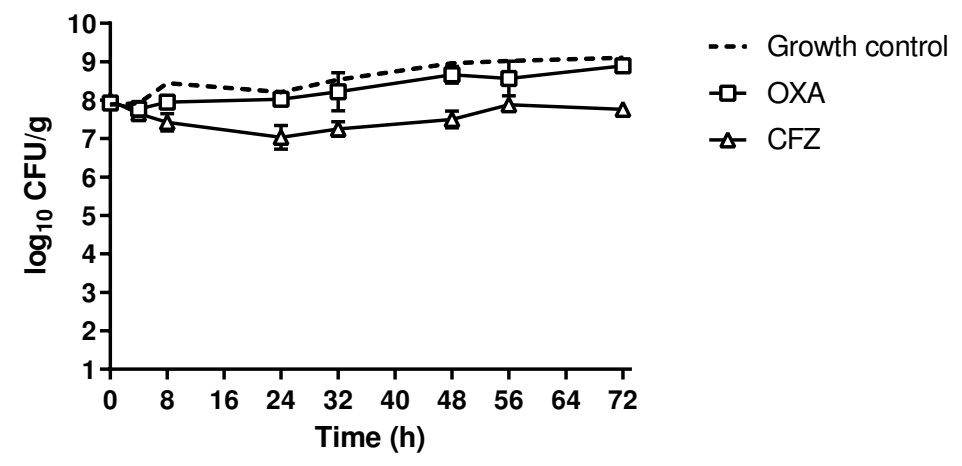

